\title{
Desechos biológicos: más allá del consentimiento informado
}

\author{
Biological waste: beyond informed consent
}

\section{Señor Editor:}

Con frecuencia acuden a los hospitales pacientes con patologías que ameritan una solución cruenta. Una de ellas, es el pie diabético, en el que la amputación si bien no es lo deseable, es lo que con mayor frecuencia ocurre. También en algunos pacientes se extraen muestras de tejidos, sueros sanguíneos y otros fluidos biológicos, los que son guardados por motivos legales o sanitarios (1).

En estos hospitales donde también se realiza docencia e investigación; se usan piezas anatómicas producto de amputaciones y otros tejidos o secreciones, con fines distintos al previsto inicialmente, sin consentimiento del paciente o familiar, lo cual involucra aspectos éticos que deben tenerse en cuenta.

Una pieza anatómica o un tejido corporal albergan información sobre la dotación genética de una persona, representan una extensión de la misma y requieren atención y cuidado bioético; a pesar de ser un residuo debe ser tratado con dignidad y con estándares de preservación (2).

Según la norma técnica de salud $\mathrm{N}^{\circ} 096$ MINSA/ DIGESA v.01 de Gestión y Manejo de Residuos Sólidos en establecimientos de Salud, para los tejidos y piezas anatómicas los métodos de tratamiento recomendados son: Enterramiento controlado, esterilización por autoclave, incineración y desinfección por microondas. El método elegido para piezas anatómicas es la incineración. Alternativamente pueden ser eliminados sin tratamiento previo en las fosas comunes de los cementerios (3). Sin embargo, la elevada frecuencia de bacterias multirresistentes presentes (en especial en miembros amputados), hace necesario que estos productos sean degradados.

El uso de este material con fines distintos a los asistenciales, sólo podrá permitirse para control de calidad o para programas de evaluación externa, sin fines de lucro, siempre que se asegure su uso en forma anónima y previo consentimiento del paciente o de la familia.

Si bien es cierto, no hay normativa nacional legal ni ética que prohíba su uso, es necesario respetar los conceptos de autonomía del paciente y dignidad de la persona humana, por ello es imprescindible, solicitar consentimiento informado para su uso.

La OPS en el 2007, estableció la guía latinoamericana para la implementación del código de ética en laboratorios de salud; ésta vincula la política y metas de la organización con las necesidades de los pacientes, estableciendo condiciones éticas para sus miembros (4). En el Perú, la Ley General de Salud $\mathrm{N}^{\mathrm{o}} 26842$, establece la necesidad y la importancia del proceso de consentimiento informado, enfocándolo más como un permiso requerido para realizar cualquier intervención médica (5). Del mismo modo, la Dirección General de salud de las personas, mediante Resolución Ministerial $\mathrm{N}^{\circ} 078-2016$, establece la necesidad de un consentimiento informado para las actividades de docencia durante la atención sanitaria (6).

1. Facultad de Medicina, Universidad Católica Santo Toribio de Mogrovejo. Chiclayo, Perú.

2. Dirección de Investigación Hospital Regional Lambayeque. Chiclayo, Perú.

a. Maestro en Epidemiología Clínica

b. Maestro en Ciencias con mención en Microbiología.

c. Médico Internista.

d. Licenciada en Biología, Microbiología y Parasitología. 
Considerando que el consentimiento informado no está destinado sólo a promover la comprensión de los pacientes con la recomendación de un personal de salud, sino que les permite rechazar procedimientos no deseados, el concepto debe entenderse en la aceptación o negativa de este.

Se propone la existencia de un consentimiento informado diseñado para uso de material biológico con fines de docencia, además de la autorización del departamento de salud ambiental en los hospitales y la opinión favorable del Comité de Ética hospitalario.

\section{Franco León-Jiménez 1,2,a,c Emma Vanesa Arriaga-Deza ${ }^{2, b, d}$}

\section{REFERENCIAS BIBLIOGRÁFICAS}

1. Del Campo J. La ética en el laboratorio clínico. CCM. 2013;17(1): 83-5. (Citado el 16 de enero del 2018) Disponible en: http://scielo. sld.cu/scielo.php?script=sci_arttext\&pid=S156043812013000100014\&lng=es

2. Observatori de Bioética i Dret. Ley 14/2007, de 3 de julio, de Investigación Biomédica. Barcelona:
Observatori de Bioética i Dret; 2007. (Citado el 16 de enero del 2018) Disponible en: http://www. ub.edu/rceue/archivos/LIB_2007.pdf

3. Ministerio de Salud. Norma técnica $\mathrm{N}^{\circ}$ 096-MINSA/DIGESA v.01.- Norma Técnica de Salud de Gestión y Manejo de Residuos Sólidos en Establecimientos de Salud y Servicios Médicos de Apoyo. Lima: Diario Oficial El Peruano; 3 de julio del 2012. (Citado el 4 de marzo 2019) Disponible en: http://sial.segat.gob.pe/normas/ norma-tecnica-salud-gestion-manejo-residuossolidos-establecimientos

4. Terrés-Speziale M. El código de ética de la Organización Panamericana de la Salud. Rev Mex Patol Clin. 2007; 54(1):6-11.

5. González-Castro A, Adín F, Cubas F, et al. Utilización de cadáveres para la enseñanza de la intubación oro traqueal. Rev esp med legal. 2017; 43(4):162-5.

6. RevillaA, Fuentes D. La realidad del consentimiento informado en la práctica médica peruana. Acta méd. peruana. 2007; 24(3):223-8. (Citado el 16 de enero del 2018) Disponible en: http://www.redalyc. org/articulo.oa?id=96624314

Recibido: 23/08/2019 